\title{
Sintomas psicóticos e cognitivos associados à busca de tratamento por dependentes de substâncias - Um estudo qualitativo
}

\author{
Psychotic and cognitive symptoms associated to treatment seeking behavior \\ - A qualitative study \\ Bruno José Barcellos Fontanella
}

\section{RESUMO}

Há algumas décadas, busca-se compreender melhor o processo subjacente ao comportamento de procura de tratamento por usuários que fazem uso nocivo ou são dependentes de substâncias psicoativas. Os modelos atualmente propostos baseiam-se principalmente na análise epidemiológica de certas características individuais quanto ao poder que têm de influenciar esse comportamento de disposição para tratamento. Objetivos: Interpretar e compreender possíveis significados pessoais associados a alterações psicopatológicas, sobre como podem se relacionar à procura de tratamento, na visão dos próprios pacientes. Método: Pesquisa qualitativa com entrevistas semidirigidas com amostra intencional de 13 dependentes de substâncias que procuraram tratamento. Resultados: Houve relatos espontâneos de alterações de forma, curso e conteúdo de pensamento e juízo de realidade, alterações de sensopercepção, de atenção, memória e linguagem. Os membros da amostra pareceram relacioná-las à motivação para tratamento. Os dados foram interpretados considerando o contexto psicocultural dos entrevistados e seus quadros clínicos de síndrome de dependência, de abstinência e de comorbidade. Conclusões: Pesquisas qualitativas contribuem para aprimorar os modelos explicativos sobre procura de tratamento por dependentes de substâncias. Investigar clinicamente alterações psicopatológicas parece poder contribuir para motivar pacientes para tratamentos específicos do uso disfuncional de substâncias.

\author{
ABSTRACT \\ During the last few decades it is aimed to better understand the process underlying treatment \\ seeking behavior by harmful or dependent psychoactive substances users. The currently proposed \\ models are mainly based on the epidemiological analysis of certain number of individual charac- \\ teristics, as they have the power to influence this behavior of readiness for treatment. Objectives: \\ To interpret and understand possible personal meanings associated with psychopathological dis- \\ orders and how they can be related to treatment seeking behavior, as described by the patients \\ themselves. Method: Qualitative study conducted on an intentional sample of 13 substance de- \\ pendents seeking for formal treatment; in-depth semi-structured interviews. Results: The par- \\ 1 Universidade Federal de São Carlos (UFSCar), Departamento de Medicina, Centro de Ciências Biológicas e da Saúde. \\ Endereço para correspondência: Bruno José Barcellos Fontanella \\ Universidade Federal de São Carlos, Centro de Ciências Biológicas e da Saúde, Departamento de Medicina \\ Rodovia Washington Luís, km 235 - 13565-905 - São Carlos, SP \\ Telefones: (19)9221-4439/(16)3351-8340. \\ E-mail:bruno@ufscar.br
}

Recebido em 5/1/2010 Aprovado em 23/3/2010 


\section{Keywords}

Substance-related

disorders, alcohol-

related disorders, patient

acceptance of health care,

psychopathology. ticipants spontaneously reported: shape, course and content thought disturbances and sense of reality, sensory perception disorders, and attention, memory and language deficits. The sample's participants seemed to relate these disorders to the treatment seeking motivations. The data were interpreted considering the interviewees' psycho-cultural context their clinical presentations (dependence or withdrawal syndromes and comorbidities). Conclusions: Qualitative research contribute to improve current models of substance dependents' treatment seeking behavior. The clinical investigation of psychopathologic disorders seem to motivate patients to specific treatments of dysfunctional use of substances.

\section{INTRODUÇÃO}

Já há algumas décadas busca-se compreender melhor o processo subjacente ao comportamento de procura de tratamento por pessoas que fazem uso nocivo ou são dependentes de substâncias psicoativas. Os modelos atualmente propostos baseiam-se na análise epidemiológica de certas características individuais quanto ao poder que têm de influenciar esse comportamento de disposição para tentar alterar o padrão de uso via tratamento ${ }^{1-3}$.

Nesse processo, um conjunto de fatores predisponentes parece influenciar o estado de disposição para tratamento, favorecendo-o ou não; são fatores relacionados a gênero, história anterior de tratamento, etnia, idade, procedência etc. A eles se somam vários outros fatores menos estruturais e mais mutáveis, relacionados ao padrão de uso e às suas consequências, tanto do ponto de vista psicobiológico quanto sociofamiliar. Desse conjunto dinâmico fazem parte também possíveis barreiras objetivas, como sistemas familiares, comunitários e jurídicos com aspectos disfuncionais. No caso brasileiro, deve-se levar em conta também o Sistema Único de Saúde e seu "Programa de Atenção Integral ao Usuário de Álcool e outras Drogas"4, cuja plena realização se dará em prazo difícil de determinar e com o qual a população e profissionais de saúde já interagem.

Diante de dimensões tão variadas a abrigarem fatores motivadores e desmotivadores tão numerosos e complexos, a resultante comportamental para uma mesma pessoa costuma ser altamente variável ao longo do tempo ${ }^{5}$. O dia a dia dos clínicos e dos familiares de usuários que fazem uso nocivo e dependentes de substâncias é usualmente permeado pelos comportamentos ambivalentes, inconstantes e erráticos dessas pessoas, seja com relação à procura por tratamento formal ou informal, ou mesmo quanto às tentativas de autotratamento. Mesmo que uma ajuda já tenha sido procurada espontaneamente, revelando maior propensão interna para um atendimento, isso não significa uma motivação permanente para tratamento ${ }^{6}$ nem assegura que, já num momento seguinte, a situação não se reverta.

A compreensão epidemiológica da utilização dos sistemas de saúde passa necessariamente pela redução a variáveis da complexidade do contexto biopsicossocial e histórico-cultural vivido por seus usuários. Os modelos re- sultantes são certamente úteis para a gestão dos sistemas e serviços, porém menos para um clínico que faça abordagens centradas em pessoas específicas ${ }^{7}$, tentando motivá-las a procurar ou aderir a uma proposta de plano terapêutico individualizado. Nesses casos, outros elementos também adquirem relevância para ajudar a fundamentar o raciocínio clínico, sobressaindo os significados psicoculturais atribuídos pelos pacientes e suas famílias aos problemas que enfrentam. Em parte, tais significados devem explicar a frequente variação comportamental sobre procura de tratamento. Algumas teorias que norteiam estudos de significados, como a teoria das representações sociais ${ }^{8}$ e a teoria psicanalítica, podem fornecer elementos úteis para explicar essa intensa variabilidade.

Por serem geralmente retrospectivas, as pesquisas sobre esse tema (significados socioculturais e pessoais) estão sujeitas a vieses de alterações de lembranças dos informantes ${ }^{9-11}$ e da interpretação que dão a essas lembranças. São também comuns os vieses de seleção amostral relacionados à alta prevalência de comorbidades psiquiátricas entre os usuários problemáticos de SPA ${ }^{11-15}$, havendo maior chance de pacientes com comorbidade(s) serem incluídos nas amostras ${ }^{16}$. A subpopulação que efetivamente procura um tratamento pode estar sujeita a motivações relacionadas primariamente ao quadro comórbido que apresenta, e não com a dependência ou uso nocivo.

A presença de sintomas psicopatológicos, comumente associados ao uso nocivo e dependência de SPA, pode ser um fator motivador para alguns dependentes procurarem tratamento. Sintomas depressivos parecem se correlacionar positivamente com motivação para ajuda interpessoal e tratamentos ${ }^{17,18}$

As alterações de pensamento e juízo de realidade e os distúrbios cognitivos são menos estudados. Neste presente artigo, continua-se analisando um corpus de entrevistas com pacientes que procuraram tratamento, o qual já suscitou outros relatórios ${ }^{19-21}$. Aqui, o objetivo principal foi compreender e interpretar significados pessoais associados a esses tipos de alterações psicopatológicas em uma amostra que efetivou tal procura. A utilização do termo "compreender" apoia-se no campo de estudo da hermenêutica, que procura conferir significados (no caso, psicológicos e psicopatológicos) a um produto cultural (no caso, as falas dos participantes) ${ }^{22}$. 


\section{MÉTODOS}

Foi utilizada a técnica de entrevista semidirigida em profundidade com dependentes de SPA, a respeito das motivações que eles próprios identificavam para procurarem tratamento formal. Escolheu-se essa técnica de coleta de dados porque o intuito da pesquisa era levantar e procurar compreender os significados pessoais para a procura de tratamento que ainda haviam sido pouco explorados na literatura médica e psicológica.

As entrevistas foram realizadas no final da década de 1990, sendo os dados coletados depois da aprovação do projeto de pesquisa pelo Comitê de Ética em Pesquisa com Seres Humanos da instituição onde foi realizada; os entrevistados assinaram previamente o Termo de Consentimento Livre e Esclarecido.

Um tema abrangente e genérico foi inicialmente proposto ("como ocorreu a procura de tratamento"), seguido, ao longo as entrevistas, por subtemas ("fatores desencadeantes"; "o que entende por tratamento"; "aspectos do uso que deseja modificar"; "por que não procurou tratamento antes"; "como imaginou os profissionais que o atenderiam"; "como eles deveriam ser"; "influência de tratamentos anteriores"). O entrevistador incentivou a expressão verbal dos entrevistados e os estimulou a exercerem um papel ativo na entrevista e a se expressarem com suas próprias palavras, visando a uma estruturação da entrevista a partir de suas características psicológicas particulares ${ }^{23}$.

Foram transcritas integralmente, resultando em um corpus de cerca de 90 mil palavras, que vem sendo submetido a uma análise dos enunciados que as correlaciona ao contexto vivido pelos entrevistados. A amostra intencional de 13 pacientes foi configurada de forma heterogênea quanto a variáveis clínicas e sociodemográficas (Quadro 1) e foi fechada pelo critério de saturação teórica ${ }^{24,25}$ e, secundariamente, pelo critério de variedade de tipos. Entrevistaram-se nove sujeitos adequados aos critérios de inclusão (descritos adiante) até que novas entrevistas não acrescentassem dados substancialmente novos aos já obtidos. Em seguida, foram incluídos quatro outros componentes que, por suas tipicidades clínicas e sociodemográficas, preenchiam lacunas da amostragem desejada: uma mulher, um dependente de opiáceos, um dependente de crack e um paciente que chegou a tratamento sob coerção.

Os critérios de inclusão foram: aderir ao tratamento inicial (três comparecimentos a consultas ou sete dias de internação); estar nas três semanas iniciais de tratamento; manter a adesão depois de resolvidas situações agudas desencadeadoras da internação ou consulta (quadro agudo de síndrome de abstinência, comportamentos disruptivos com crises familiares, intoxicação aguda grave etc.); apresentar diagnóstico de dependência de ao menos uma SPA (CID-10: F1x.2); ter queixa principal relacionada ao diagnóstico e concordar em participar.
Quadro 1. Caracterização da amostra: algumas variáveis sociodemográficas e clínicas

A. 50 anos, branco, casado, publicitário, desempregado, dependente de álcool há 15 anos, uso nocivo de cocaína intravenosa há 20 dias

B. 29 anos, negro, casado, eletricista, dependente de álcool há sete anos

C. 18 anos, branco, solteiro, técnico de telefonia, desempregado, dependente de cocaína intranasal há dois anos

D. 24 anos, branco, solteiro, sem profissão, não trabalha, dependente de cocaína intranasal há cinco anos

E. O\} 3 9 \text { anos, branco, viúvo, engenheiro, empregado, dependente de álcool há } dois anos

F. 36 anos, branco, casado, serralheiro, dependente de álcool há sete anos

G. $\quad$ \ 22 anos, branco, solteiro, comerciário, dependente de cocaína intranasal há três anos

H. Thomossexual, 29 anos, branco, solteiro, comerciário autônomo, dependente de cocaína intranasal há dois anos

I. 39 anos, branco, casado, desenhista, dependente de álcool há quatro anos

J. $\quad$ + 20 anos, parda, solteira, sem profissão, não trabalha, dependente de maconha há um ano

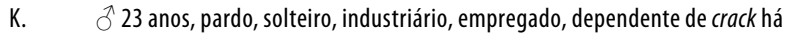
um ano

L. $\quad 43$ anos, pardo, casado, industriário, dependente de álcool há seis anos

M. 34 anos, branco, solteiro, aposentado por invalidez, dependente de codeína (por via oral, anteriormente por via intravenosa) há nove anos

\section{RESULTADOS}

\section{Percepção de alterações de pensamento e juízo de realidade}

O entrevistado E. relatou durante a entrevista algumas prováveis alterações paranoides do conteúdo de pensamento. Supôs que seus comportamentos, relacionados a esses pensamentos, tivessem impactado emocionalmente seus filhos e, sendo assim, percebeu tais alterações como fator para a decisão de rever seu padrão de consumo de álcool:

"Não, não teve nada traumático. O que teve com os meus filhos é de eu... de chegar bêbado em casa... e a... achar que tem gente espiando. 'Tem gente na janela, tem gente na porta!' Para meus filhos, isso deve ter sido traumático pra eles." (E.)

É chamativa a associação entre uso de álcool e essas alterações de juízo de realidade relatadas pelo paciente. Ele apresentava um quadro fóbico social como comorbidade e esses juízos falsos podem ter sido resultado de um estado de ansiedade ainda mais exacerbado, talvez induzido pelo álcool ou consequente a episódios de síndrome de abstinência. Essa citação da entrevista de E. parece ilustrar o que foi postulado há quase quatro décadas por Woodruff et al. ${ }^{13}$. Relataram, sobre a amostra estudada, que os dependentes de álcool com distúrbios do conteúdo de pensamento procuraram mais tratamento do que os que não apresentavam tais alterações. 
Sabe-se que os usuários de cocaína estão fortemente sujeitos a sintomas psicóticos delirantes/deliroides e alucinatórios ${ }^{26}$, ocorrendo isso, sobretudo, com os que a usam na forma de crack ou por via intravenosa ${ }^{27}$. Na amostra estudada, não havia usuários por via intravenosa e apenas um era usuário de crack; todos os demais a utilizavam por aspiração. Apesar disso, a menção a sintomas paranoides foi comum:

"Fica encanado que a polícia vai aparecer a qualquer instante para pegar ele. Os usuários chegam a se sentir perseguidos. Não tá acontecendo nada, mas [falam] 'tem alguém atrás da porta!', 'vamos lá ver, tem alguém atrás da porta!'. Só que não abre a porta! Só fica ali, encanado que tem alguém ali..." (J.)

"Comecei a cheirar demais e quando cheiro demais, não consigo ficar com ninguém. Não falo, não gosto de parar onde tem pessoas. Parece que tem um monte de gente querendo me pegar ali no meio, todo mundo está olhando para você, parece que você é a atração... da peça..." (C.)

O entrevistado K. mencionou supostas vivências psicóticas de colegas, sendo chamativas as sutilezas da descrição que fez. Com suas palavras, relatou que as alucinações ou ilusões visuais de seus colegas usuários de crack ocorriam, sobretudo, no campo visual superior, conforme depreendeu a partir das observações que fez durante sessões grupais de uso. Já os participantes D. e H. descreveram, como se segue, o modo como vivenciaram algumas alterações de pensamento:

"tava... paranoia... ligadeira, ligação, encanação, tem alguém atrás de mim... tem alguém, sabe? Do lado... querendo me matar. O cara tá olhando pra mim: tá falando que tô ligado, tô pescando. O garçom passou, deixou cair uma garrafa, você já fica esperto, sabe? Um tá batendo boca com outro, você já acha que écom você. Tem dois batendo boca, o cara olhou, cê fala: 'é comigo...É... é..."' (D.)

"- A lembrança desse dia deve ter ficado na sua cabeça como algo ruim. Contribuiu para você parar?

- Acredito que não. Porque nesse dia usei a maconha de novo, nunca usei maconha... No final de março compramos e fomos fumar. Saí completamente fora do ar. Brigava comigo mesmo. Um lado queria fazer tal coisa, mas o outro lado queria fazer outra. Não sabia se era eu, com meu lado consciente, ou o meu lado inconsciente. Foi uma coisa ruim, muito ruim. Foram três experiências ruins. Dentro do grupo, a gente conversava disso. 'Vamos parar, vamos parar.' Principalmente sob o efeito da substância, da cocaí- na, a gente sempre falava. Mas isso era por falta de assunto, de outra coisa pra falar." $(\mathrm{H}$.

Há poucos elementos para afirmar, mas essa menção de H. lembra uma alteração da forma de pensamento ou talvez uma alteração da vontade (hipobulia) ou mesmo uma alteração da consciência da unidade do eu.

As possíveis alterações de juízo de realidade inferidas a partir dos relatos dos participantes foram por eles denominadas de diferentes modos: "paranoias" (D., G. e H.), "neuroses" (C., H. e K.) ou "encanações" (D. e G.). Seriam provavelmente classificáveis psicopatologicamente como vivências de ideias deliroides de conteúdo persecutório ("parece que tem um monte de gente querendo me pegar ali no meio" - C.), descritas também de forma a lembrar uma interpretação delirante ("dois batendo boca, o cara olhou, cê fala: 'é comigo"' - D.). Foram, entretanto, frustras e aparentemente sem outros desdobramentos ideativos, tendo mantido os pacientes um pensamento organizado, pelo que se infere de seus relatos.

Por conviverem com subgrupos culturais de usuários de substâncias, esses participantes conheciam a frequente associação entre uso de cocaína e "paranoia". Isso pode ter facilitado suas críticas sobre tais sintomas, quando eles próprios os vivenciaram, mesmo que tenham sido críticas apenas parciais. Em geral, identificaram essa possível relação causa-efeito, mas simultaneamente em alguns momentos cogitaram serem plausíveis alguns conteúdos dos juízos alterados. Isso pareceu gerar no entrevistado D. algumas reações ambivalentes a esse tipo de sintoma. Por esse motivo (alteração de juízo de realidade), parece que se indispôs apenas parcialmente com a problemática do uso de cocaína, talvez por isso postergando a procura de tratamento, como se pode inferir a partir do seguinte diálogo:

"- Na hora você não achava que é cocaína... ou acha$v a$ ? [fala do entrevistador]

- Não... O cara acha... você sabe que é pó que te deixa assim. Mesmo assim acreditava, vai ver ele tá olhando mesmo, tal... Todas as loucuras, todos as pensamentos passando na sua frente, na sua cabeça, rápido. Me incomodava. As duas coisas ao mesmo tempo. Seu amigo... você vai conversar com ele, tal, né? 'Tá ligado? Tô. Vamos dar uma aí', num sei o quê, tal, ia acompanhando pro bar. Aí tomava uma ceva, tentava descontrair, conversar, mexer com mulherada, tal..." (D.)

Nesse trecho, esse entrevistado aparentemente se refere também a um curso de pensamento acelerado.

Já a menção a possíveis ideias de grandeza foi feita por um entrevistado também incomodado com os conteúdos paranoides que vivenciava:

"Vi que tava perdendo tempo, me afastei... da sociedade. E em função de cheirar cocaína e ficar nas 
neuroses, nas fantasias que a gente mesmo cria. E outros amigos... tava andando com um grupo de amigos que só usam cocaína, não tem estímulo nenhum pra outras coisas...

- Sobre as neuroses, fantasias...

- Que a gente era o dono do mundo, a gente era o dono da verdade, que a sociedade tava completamente errada e nós estávamos certos." $(\mathrm{H}$.

J. disse que "encanou" que seu pai apareceria durante uma sessão de uso de cocaína, o que pareceu contribuir indiretamente, segundo se pode inferir a partir de seu relato, para sua concordância em procurar ajuda de um profissional:

"- Ter a over não te fez mudar de ideia sobre a quantidade da cocaína? [fala do entrevistador]

- Isso foi mais por parte de meus amigos, mesmo. Eles mais controlam do que eu própria: 'Você acabou de ter este problema então hoje você não vai cheirar', 'Você hoje não vai cheirar muito', estas coisas. Mas, assim... estou ciente do que estou fazendo agora. Sei a hora quando tenho que parar. Agora o que é mais ruim é na hora que estou cheirando encano no meu pai e na minha mãe, qualquer coisa assim. Aífico mal e resolvo parar, entendeu?" (J.)

Também associando esse tipo de vivência psicopatológica à vontade de interromper o uso de cocaína, o participante G. passou a não mais considerar que o uso que fazia era "social" ao se dar conta de que passou a ter "medo das pessoas, de tudo".

Por sua vez, K. expressou temer passar a vivenciar os sintomas aparentemente psicóticos que seus colegas descreviam, prevendo que isso aconteceria consigo. Segundo o que relatou, procurou interromper o uso antes:

"A pessoa falava assim: 'Tá lá, e olha o cara olhando a minha mulher.' 'Mas tá onde?' 'Olha o olho do cara, aí" Apontavam para a parede toda fechada. 'Não, não tem ninguém!' 'Que isso? Olha a sobrancelha do cara!' Ficava apontando para um buraco de prego na parede, querendo atirar. 'Não, abaixa este revólver, não tem nada aí não.' 'Vou deixar quieto, mas vou matar.' De repente eles já corriam para fora, subiam em cima do telhado. Então ficava percebendo aquilo e pensava 'será que algum dia vou ficar assim?' Só que não esperei para saber. Já saí fora." (K.)

\section{Percepção de alterações cognitivas}

O incômodo de se perceber com alguns déficits cognitivos pareceu contribuir para que alguns entrevistados quisessem rever o padrão de uso nocivo de substâncias. Foram relatadas aparentes alterações do processamento geral de informações (memória, pensamento ou raciocínio):
"- Em algum momento, você pensou em morrer...? [fala do entrevistador]

- Não. Que me lembre, não. Só se teve... uma hora mais... crítica, posso ter até pensado, mas... que nem falei, tem coisa que às vezes fazia e não me lembrava. Levantava no outro dia: 'não lembro de nada, né'. Cheguei a pôr minha carteira num lugar e no outro dia ficar dois, três dias procurando ela. Não me lembrar. Uma vez pus... cansei do peso, aí pus ela debaixo do... no... atrás do banco do carro. Fiquei três dias procurando essa carteira. Não lembrava não." (F.)

"- Já havia todo um movimento de procurar um tratamento... [fala do entrevistador]

- Havia, porque já estava cansado... sabe? Era só cocaína, cocaína, cocaína... Chegou uma hora que estava muito cansado, estava muito magro, tava... acho que nem pensamento direito não tava... nem tava... A gente fica meio grogue, grogue, grogue... Hoje vejo que tenho os sentidos mais... assim... palavras." (D.)

"Sou engenheiro, né? faço cálculo... Então eu... eu... não tinha mais raciocínio pra isso. Então a única coisa que fazia era... praticamente ficava no bar e... ouvindo piada de bar, dava risada com os amigos, ia pra casa e desmaiava à noite. Você não pensa nada de sério, nada..." (E.)

O participante E. também referiu ter considerado seu "estado mental completamente inútil" quando a queda de seu rendimento intelectual repercutiu em seu trabalho. O entrevistado D. pareceu referir-se a uma alteração de inibição de pensamento; observe-se que ele fez uma associação da degradação física por que passou (perda de peso) com as alterações de raciocínio, aparentemente considerando nestas duas áreas (física e psíquica) quais eram os limites que podia suportar.

Alguns participantes incomodaram-se por não se lembrarem "de nada" ocorrido no dia anterior (F.) (amnésia anterógrada?), por não pensarem "nada de sério" (E.) (dificuldades de concentração?) e por não conseguirem se expressar verbalmente "direito" (D.), angustiando-se todos, portanto, por perceberem alguns rendimentos psíquicos básicos declinando. Outros exemplos:

"Seu raciocínio fica mais lento também, fica mais lento pra raciocinar. Tinha dias que eu não ia trabalhar, perdia a hora, não aparecia para trabalhar. Ficava, dois, três dias. Meu pai brigava comigo. Isso aí prejudicou muito. Por isso perdi a confiança dele." (G.)

"- Por que estava afetando a vida profissional? [fala do entrevistador] 
- Em tudo. Primeiro, eu já estava demonstrando para todo mundo. E meu raciocínio também estava muito lento, para pegar um desenho, um painel, para raciocinar rápido, já estava muito lerdo pra raciocinar." (L.)

\section{DISCUSSÃO}

A utilização da técnica de entrevista semidirigida com temas abertos aparentemente favoreceu insights dos participantes e permitiu que o pesquisador inferisse hipóteses sobre motivações internas (subjetivas) para procura de tratamento. Dentre as variáveis atuantes no complexo sistema motivacional envolvido no processo de procura de tratamento por dependentes de substâncias psicoativas, algumas são como estas (subjetivas) e, de início, somente podem ser exploradas cientificamente a partir das perspectivas dos próprios pacientes. A fenomenologia, que fundamenta parcialmente alguns métodos qualitativos e o conhecimento psicopatológico, teve aqui, portanto, um emprego duplamente útil. Observe-se, no entanto, que a coleta de dados foi dirigida primacialmente para os motivos de procura de tratamento, tais como relatados pelos entrevistados, e não foi voltada para uma anamnese psicopatológica, propriamente. Isso impede uma descrição mais detalhada de algumas vivências relatadas pelos participantes.

As dimensões motivacionais aqui abordadas (sintomas psicóticos e a gama de alterações de funções cognitivas) não compunham os pressupostos do pesquisador antes da pesquisa, por serem pouco citados na literatura sobre motivação para tratamento, ao contrário dos sintomas depressivos. Essas dimensões foram espontaneamente trazidas à tona pelos entrevistados, significando uma provável valoração subjetiva desses fenômenos.

Nesse sentido, é chamativo o nível de detalhamento fornecido por alguns entrevistados, todos sem conhecimentos técnicos psicopatológicos, o que sugere ter havido movimentos introspectivos de procura de nexos causais explicativos dessas vivências ansiogênicas. Conflitos psíquicos significativos, envolvendo a motivação para continuar usando e ao mesmo tempo a motivação de rever esse comportamento, parecem ter surgido quando esses pacientes passaram a cogitar alterar o padrão de uso via tratamento formal. Isso pode ter favorecido uma avaliação pormenorizada dos benefícios e riscos em jogo, assim como uma maior atenção às características dessas vivências, que antes provavelmente eram pouco usuais em sua vida.

A percepção de perdas de habilidades do espectro cognitivo parece ter sido mais valorizada quando foram relacionadas a prejuízos para o trabalho. Isso é coerente com o já postulado na década de $1970^{9}$ e ratificado mais recentemente ${ }^{28}$ : repercussões nessa área de funcionamento social seriam fatores que frequentemente levam "pessoas" a se tornarem "pacientes".

Embora as ideias deliroides de grandeza possam ocorrer nas intoxicações com cocaína (substância de uso de cinco entrevistados), elas foram citadas por apenas um deles, em associação com ideias paranoides (H.). A pouca valorização desse tipo de vivência, caso tenha ocorrido com outros entrevistados, talvez possa ser explicada por ela ser percebida como egossintônica e vir ao encontro das chamadas defesas psicológicas maníacas, provavelmente comuns nessa população de usuários. Se foi assim, teriam de fato contribuído pouco para a procura de tratamento.

Avaliações subjetivas desses tipos de desconfortos foram feitas aparentemente de forma constante ao longo da história de uso nocivo dos participantes. Nesta amostra, a importância relativa que tiveram como motivador para tratamento, diante de outros fatores, não é possível de ser aferida. Estudos recentes sugerem que o estado psiquiátrico dos pacientes colabora, de modo geral, embora de maneira não muito impactante, para que ocorra o reconhecimento do problema do uso problemático de substâncias. Esse reconhecimento, por sua vez, contribui para a disposição para tratamento ${ }^{2}$. Entretanto, os sintomas depressivos talvez sejam os mais influentes ${ }^{18}$.

\section{CONCLUSÕES}

Nas pesquisas com questionários estruturados, os participantes devem apontar a presença e a intensidade do que já foi previsto pelo pesquisador como prováveis componentes do estado de disposição para tratamento. Diferentemente, nesta presente pesquisa, valorizou-se o ponto de vista dos próprios componentes da amostra sobre o que viveram. Somente depois, o pesquisador procurou compreendê-los a partir de seus próprios referenciais teóricos. Trata-se, então, do emprego de uma perspectiva compreensiva êmica, em contraposição à perspectiva ética de pesquisas que anteveem as possíveis respostas.

Os resultados de ambos os tipos de pesquisa (qualitativas e quantitativas) progressivamente complementam e aperfeiçoam os modelos explicativo-compreensivos sobre o tema. Estudos como o de Rapp et al.2 exemplificam a sofisticação teórico-metodológica resultante das pesquisas realizadas nas últimas décadas.

O conhecimento das possibilidades vivenciais dos pacientes aqui descritas, a partir de uma amostra não representativa da população, pode ser útil aos clínicos-gerais e psiquiatras, caso as considerem plausíveis diante das situações clínicas com que se defrontam em seus cotidianos profissionais. A validade externa de pesquisas qualitativas apoia-se, sobretudo, nesse tipo de validação clínica pelos leitores dos relatórios, quando entram em contato, ao mesmo tempo, com os elementos hipotetizados nos estudos e com seus próprios pacientes.

É possível que a investigação de sintomas e alterações psicopatológicas, mesmo nos atendimentos de saúde ines- 
pecíficos (isto é, com o motivo da consulta não se relacionando ao uso nocivo/dependência, como preferencialmente ocorre nos atendimentos por especialistas clínicos gerais), possa contribuir para motivar pacientes para tratamentos específicos relativamente ao uso disfuncional de substâncias psicoativas. Considerando a larga cobertura populacional do SUS brasileiro, o desafio seria sensibilizar e manter capacitados seus profissionais para a suspeição precoce de diagnósticos e motivação dos pacientes para aceitarem encaminhamentos para outros serviços especializados. O "Programa de Atenção Integral ao Usuário de Álcool e outras Drogas" do SUS (2009) reafirma a política de valorização da Atenção Primária à Saúde, hoje se organizando a partir das equipes que compõem as Unidades de Saúde da Família, incluindo seus médicos, no papel de clínicos-gerais. Quanto ao álcool, especificamente, há instrumentos relativamente simples e efetivos para cumprir essas tarefas em larga escala e validados na APS (CAGE, AUDIT e as intervenções breves) que trazem embutidas as possibilidades de investigação propedêutica de sintomas de alterações psicopatológicas. Portanto, uma capacitação que focalize esses instrumentos pode também permitir uma capacitação mínima nessas habilidades. Para esse tipo de capacitação, os resultados aqui apresentados podem contribuir, sendo inclusive a técnica utilizada (entrevistas semidirigidas) análoga ao método clínico empregado pelos generalistas de valorização da expressão livre dos pacientes (em vez de anamneses mais focadas).

Os resultados obtidos nesta investigação, assim como nas outras empreendidas sobre o mesmo corpus de entrevistas, foram limitados por fatores relativos à amostragem. Não foram entrevistados dependentes de substâncias pertencentes às subpopulações que aparentemente chegam ainda menos aos serviços assistenciais (moradores de rua, pessoas do meio rural e da terceira idade). Pessoas com comorbidades específicas e importantes como a AIDS também não foram entrevistadas, assim como representantes das subpopulações dos que não aderiram a um tratamento já procurado ou dos que nunca o tenham procurado.

\section{AGRADECIMENTOS}

Ao Prof. Dr. Egberto Ribeiro Turato (FCM-Unicamp), orientador da tese de doutorado na qual este artigo está parcialmente baseado.

\section{REFERÊNCIAS}

1. Xu J, Wang J, Rapp RC, Carlson RG. The multidimensional structure of internal barriers to substance abuse treatment and its invariance across gender, ethnicity, and age. J Drug Issues. 2007;37(2):321-40.

2. Rapp RC, Xu J, Carr CA, Lane DT, Redko C, Wang J, et al. Understanding treatment readiness in recently assessed, pre-treatment substance abusers. Subst Abus. 2007;28(1):11-23.
3. Rapp RC, Xu J, Carr CA, Lane DT, Redko C, Wang J, et al. Understanding treatment readiness in recently assessed, pre-treatment substance abusers. Subst Abus. 2007;28(1):11-23.

4. Brasil. Ministério da Saúde. Portaria no 2.048/GM, de 3/9/2009, que aprovou o Regulamento do Sistema Único de Saúde (SUS) e dá outras providências, 2009.

5. Windle M, Miller-Tutzauer C, Barnes GM, Welte J. Adolescent perceptions of help-seeking resources for substance abuse. Child Dev. 1991;62(1):179-89.

6. Pinsky I, Silva E, Marques AC, Formigoni M. Abandono de tratamento por dependentes de álcool e drogas: um estudo qualitativo dos motivos. Revista ABP-APAL. 1995;17(4):150-4.

7. Stewart M, Brown JB, Weston WW, McWhinney IR, McWilliam CL, Freeman TR. Medicina centrada na pessoa: transformando o método clínico. Porto Alegre: Artmed; 2010.

8. Moscovici S. Representações sociais. Investigações em psicologia social. 2. ed. Petrópolis: Vozes; 2003

9. Zola IK. Pathways to the doctor-from person to patient. Soc Sci Med. 1973;7(9):677-89.

10. Hingson R, Mangione T, Meyers A, Scotch N. Seeking help for drinking problems: a study in the Boston Metropolitan Area. 1982;43(3):273-88.

11. Ross HE, Lin E, Cunningham J. Mental health service use: a comparison of treated and untreated individuals with substance use disorders in Ontario. Can J Psychiatry. 1999;44(6):570-7.

12. Montoya ID, Haertzen C, Hess JM, Covi L, Fudala PJ, Johnson RE, et al. Comparison of psychological symptoms between drug abusers seeking and not seeking treatment. J Nerv Ment Dis. 1995;183(1):50-3.

13. Woodruff RA, Guze SB, Clayton PJ. Alcoholics who see a psychiatrist compared with those who do not. Q J Stud Alcohol. 1973;34(4):1162-71.

14. Finney JW, Moos RH. Entering treatment for alcohol abuse: a stress and coping model. Addiction. 1995;90(9):1223-40.

15. Rounsaville BJ, Kleber HD. Untreated opiate addicts. How do they differ from those seeking treatment? Arch Gen Psychiatry. 1985;42(11):1072-7.

16. Galbaud du Fort G, Newman SC, Bland RC. Psychiatric comorbidity and treatment seeking. Sources of selection bias in the study of clinical populations. J Nerv Ment Dis. 1993;181(8):467-74

17. Ryan RM, Plant RW, O'Malley S. Initial motivations for alcohol treatment: relations with patient characteristics, treatment involvement, and dropout. Addict Behav. 1995;20(3):279-97.

18. Cahill MA, Adinoff B, Hosig H, Muller K, Pulliam C. Motivation for treatment preceding and following a substance abuse program. Addict Behav. 2003;28(1):67-79.

19. Fontanella BJB, Turato ER. Barreiras na relação clínico-paciente em dependentes de substâncias psicoativas procurando tratamento. Rev Saude Publica. 2002;36:439-47.

20. Fontanella BJB, Mello GA, Demarzo MMP, Turato ER. Percepção da síndrome de dependência por pacientes em tratamento. J Bras Psiquiatr. 2008;57:196-202.

21. Fontanella BJB, Turato ER. Spontaneous harm reduction: a barrier for substance-dependent individuals seeking treatment? Rev Bras Psiquiatr. 2005;27(4):272-7.

22. Johnson AG. Dicionário de sociologia: guia prático da linguagem sociológica. Rio de Janeiro: Jorge Zahar; 1997.

23. Bleger J. Temas de psicologia: entrevista e grupos. 4. ed. São Paulo: Martins Fontes; 1989.

24. Fontanella BJB, Ricas J, Turato ER. Amostragem por saturação em pesquisas qualitativas em saúde: contribuições teóricas. Cad Saude Publica. 2008;24(1):17-27.

25. Glaser G, Strauss A. The discovery of grounded theory: strategies for qualitative research. New York: Aldine de Gruyter; 1967.

26. Smith MJ, Thirthalli J, Abdallah AB, Murray RM, Cottler LB. Prevalence of psychotic symptoms in substance users: a comparison across substances. Compr Psychiatry. 2009:50(3):245-50.

27. Morton WA. Cocaine and psychiatric symptoms. Prim Care Companion J Clin Psychiatry. 1999;1(4):109-13.

28. Nwakeze PC, Magura S, Rosenblum A. Drug problem recognition, desire for help, and treatment readiness in a soup kitchen population. Subst Use Misuse. 2002;37(3):291-312. 